\title{
Golden Years, Wise Mentors and Old Fools: An Updated Typology of Older Characters in British TV Advertising
}

\author{
Dennis A. Olsen, ${ }^{1}$ University of West London, United Kingdom \\ Charlotte Scott, University of West London, United Kingdom
}

\begin{abstract}
This paper presents the results of a media content analysis of character types employed for adults aged 50 years or over in contemporary UK TV advertising. Picking up on pre-existing typologies in the UK, a total of eight distinct character types are identified in our 2020 sample, including the Golden Ager, Perfect Grandparent, Mentor or Legacy, Comedic, Coper, Celebrity Endorser, Happy Couple, and Jane or Joe Public. The study concludes that the observed broadening of character types reflects a reduction in ageist views within $U K$ advertising, and that recurring themes of, for example, romance are starting to break with long-standing ageist taboos.
\end{abstract}

Key words: Image of Aging, Advertising Research, Typology, United Kingdom

\section{Introduction}

Typological approaches to investigating, organizing and describing characters and patterns of behaviors that are featured in media content have a long tradition in a variety of academic disciplines, both in the humanities and social sciences (Olsen 2019a). Arguably, one of the most famous typologies is by Russian folklorist and researcher Vladimir Propp. In his 1928 book Morphology of the Folk Tale, Propp looked at one hundred Russian folk tales for his structural analysis and identified, among others, seven abstract character functions, or schematic types, that were commonly found within the tales' narratives.

The use of schematic types and functions also plays a significant role in advertising - both in its creation and in its analysis. As advertising relies heavily on cognitive short-hand in the form of stereotypes to tell its stories, advertising creatives make regular use of established character types and situations to draw upon preexisting, shared knowledge in the minds of their audiences (Schwender 2015; Idris and Sudbury-Riley 2016). The use of stereotypical images to represent specific groups in advertising is certainly not new. The roles played by women, men, ethnic groups, LGBTQ+ and other social groups in advertising are well documented (e.g., O'Barr 2012; Koinig, Diehl and Terlutter 2020). What makes stereotypical media portrayals interesting is not the fact of their existence, but rather the distinct forms used to represent specific groups of people. Advertising lends itself well to this type of investigation, because it reflects contemporary trends and embodies societal images of particular groups (Otrebski 2015).

A recent literature review by the Centre for Ageing Better (2020) concluded that ageism, the systematic stereotyping of and discrimination against older people (Butler 1975), was 'still rife' in the UK, including in its media. Considering the country's increasingly aging population, with the share of persons aged 50 years or over now at almost 38\% of the UK's total population (Eurostat 2021), this conclusion is a cause for concern. Although ageist portrayals may provide comfort for younger persons by maximizing group differences and reducing the anxiety associated with growing old, they deny the individuality of aging and ignore the extreme heterogeneity which exists within the older population. The most salient feature of ageism is not so much its depiction of 'positive' or 'negative' images associated with old age, but far more its limiting effect. "What makes a portrayal racist, sexist, or ageist is the repetition of the same types of behaviors over and over again to the point of limiting, denying, or excluding other potentials. A full range of human potentials is denied the individual; constricted roles become the norm" (Ansello 1977, 255). An analysis of character types currently employed in advertising can shine a light on the ageist ideas that prevail within society.

The current study is framed by two theoretical concepts: cultivation theory and vitality theory. Nowadays, mass media are largely responsible for imparting knowledge and ideas of the unknown, thereby critically helping to shape and distribute stereotypes. In times where personal contact between the generations is dwindling, the media become a crucial source of information on aging and older people (Russow and Koll-Stobbe 2015). Cultivation theory addresses this assumption, and centers on the core hypothesis that the more time individuals spend consuming media content, the closer their views align to the reality created by the media. In other words, a frequent and high exposure to media images impacts the viewer's perception of social reality in the direction of the reality constructed by the media (Gerbner et al. 2002). Although cultivation theory has been met with some criticism (e.g., Bryant 1986; Berger 2005; Griffin 2012), to date the main principles of the theory are still

\footnotetext{
1 Corresponding Author: Dennis A. Olsen, St Mary's Road, London School of Film, Media and Design, University of West London, London, W5 5RF, United Kingdom. email: Dennis.Olsen@uwl.ac.uk
} 
considered accurate. It is widely accepted within academic discourse that the media contribute to a person's socialization. Some (media) scholars even argue that today's socialization in the industrialized world largely equals socialization through media (Schmidt and Spieß 1995; Schwender, Hoffmann and Reißmann 2013; Cluley 2017). Although it is evidently only one of many socialization agents, it is particularly effective because almost the entire populations of modern societies are constantly exposed to media content. Hasebrink (2016) notes that the question of long-term influences regarding media remains highly relevant.

This effect on the audience's perception of reality is enhanced when the images portrayed align with the real world. Therefore, individuals learn about the world in terms of gender roles, age stereotypes and cultural paradigms from the media; a phenomenon that is particularly pronounced in children but can be seen throughout a person's lifetime (Busselle and Van den Bulck 2020). In modern industrialized societies, where commercial media outlets are omnipresent, a high contact rate between individuals and advertisements is almost inevitable. Due to the frequent and cumulative occurrence of mass media, the opportunities to influence the creation of stereotypes are therefore great. Mass media are particularly critical because they mediate between collective and individual experience by offering typical interpretations for supposedly typical problems (Hesse and Gelzleichter 1993). Their special position lies in the fact that they have a defining power and the resources to make their version of the world and events generally available to the public, and "offer powerful interpretations of how to understand these events and the people or groups involved in them" (Hall et al. 1978, 57). "Consequently, media messages that stereotype individuals by their concentrations, frequencies, and omissions become part of our long-term memory" (Lester 1997).

In addition, vitality theory assumes that within a society, social groups of greater number and social status have greater 'vitality' (Ehala 2010). A group that possesses more vitality will receive much greater support and representation in society as a whole, including in the media (Harwood and Roy 2005; Kessler, Schwender and Bowen 2010; Otrebski 2015). If those groups that possess greater vitality are better represented in the media, by looking at how specific groups are portrayed, one can glean an insight into the social standing and the position of these people within a society. This theory stands somewhat in contrast to cultivation theory. Rather than analyzing media content for the effect it has on a society, it looks at media as a reflection of society and a tool for understanding the social standing of groups within it. Both theories combined, however, emphasize how productive media, and thus advertising, investigation can be in the context of the examination of representation of older people. They also point out the dynamic nature of the media and advertising, which limits findings, among others, to a specific point of time. In consequence, this means that developments of any kind beyond the investigation period can only be inferred from studies on media and advertising, when put in the context of comparable previous data points.

\section{Typologies of Older Adults in UK Adverts}

Whilst crafting typologies for older adults in advertising has a long tradition, and is amongst the most popular research approaches in, for example, Germany (Olsen 2019a), in the UK, very little research has made use of typological approaches. A systematic literature review of studies into the image of old age and aging in UK advertising identified two sets of typologies to date.

In her investigation of visual media, Whitfield (2001) defines six categories: 'the frail little old lady/man victim', 'the benign old granny and/or granddad', 'the deliriously active and happy couples and individuals', 'younger women playing the role of older women', 'the powerful older male' and 'mixed images'. Whilst Whitfield provides succinct descriptions for the first five categories, the type 'mixed images' appears to be a collecting pond for what she refers to as less frequent but "more complex images" (Whitfield 2001, 13). The description of this final category remains short and vague, raising questions about the full range of portrayals that older adults were admitted at the time of the investigation. In combination with transparency issues in terms of methodology and sample composition of the study, which included but was seemingly not limited to advertising, this might be the reason why Whitfield's work has not received much attention in the academic discourse. These transparency issues pose challenges for using the types as a point of reference for future advertising research.

Williams et al. (2010) also identify a total of six types throughout their three studies published between 2007 and 2010. Accordingly, British print advertising at the time portrayed older characters either as 'Golden Agers', 'Perfect Grandparents', 'Mentors', 'Comedic', 'Copers' or 'Celebrity Endorsers'. Although providing only little description beyond the name for each type, the typology has subsequently been picked up - most recently, in research on British magazine adverts by Ylänne (2020) — making it the predominant typology of older characters in advertising in the UK to date. 


\section{Research aims}

This paper has two research aims:

(i) to evaluate whether the portrayals of older characters in contemporary British TV advertising still fit the types identified by Williams and colleagues; and

(ii) to identify potential new types and provide a fuller description for each existing character type.

\section{Study Design}

TV commercials featuring people aged 50 years and older were examined using media content analysis (Macnamara 2005). The sample comprised adverts aired in the UK on ITV, Channel 4 and Channel 5 during prime-time $(6 \mathrm{pm}-11 \mathrm{pm})$ between 1 and 14 September 2020. Every commercial aired during this time was included in the analysis, resulting in a total of 6,228 adverts.

The initial assignment to the individual Williams et al. (2010) types was part of a larger coding exercise and involved two female and two male coders, aged between 22 and 74 years. All coders were based in the UK. Their selection was intended to counteract potential cultural, sex and/or age biases during the coding process (Olsen 2019b). Coding during this initial stage took place independently (Lombard, Synder-Duch and Bracken 2002), before entering a collaborative phase for the qualitative type creation and description. A virtual workshop was organized, during which each type and their common features were discussed and agreed upon amongst coders. The workshop lasted approximately four hours and formed the basis for the description of each character type.

\section{Findings}

Discounting repetitions of commercials, the sample featured a total of 167 unique characters estimated to be 50 years or older. Table 1 shows their distribution between character types identified, illustrating that the full range of types reported by Williams and colleagues in 2010 could still be found in current British TV commercials. This is in addition to two new types.

Table 1: Distribution of character types within the current sample and previous studies (in \%)

\begin{tabular}{lccc}
\hline & Olsen and Scott (2021) & Ylänne (2020) & Williams et al. (2010) \\
\hline Celebrity Endorser & 18.0 & 14.3 & 10.0 \\
Golden Ager & 17.4 & 30.5 & 35.7 \\
Jane or Joe Public* & 15.6 & - & - \\
Perfect Grandparent & 11.4 & 9.2 & 7.7 \\
Comedic & 10.3 & 0.6 & 5.9 \\
Happy Couple* & 10.2 & - & - \\
Coper & 9.6 & 27.0 & 24 \\
Mentor or Legacy & 7.8 & 8.3 & 14.5 \\
*new character type & & &
\end{tabular}

Accordingly, every third older adult observed in current British TV advertising was either a 'Celebrity Endorser' (18.0\%), or a 'Golden Ager' (17.4\%). The third most common character type was one of the two newly identified categories - the 'Jane or Joe Public' (15.6\%) — followed by the 'Perfect Grandparent',

'Comedic', 'Happy Couple' and 'Coper'; all of whom occurred similarly often in the sample (between $9.6 \%$ and $11.4 \%)$. The type least often encountered was that of the 'Mentor or Legacy' (7.8\%). This pattern of distribution is a distinct departure from previous studies, where over half of older characters appeared to be either 'Golden Agers' or 'Copers'.

More interesting than the mere frequency of occurrences of the character types are the stereotypical presentations used to portray older people. To shine a more detailed light on what roles and types of behaviors were admitted to older adults in 2020 , the following presents the qualitative description for each character type based on our sample of 167 older adults. This starts with the six types by Williams et al. (2010): 


\section{Golden Ager}

The Golden Agers are young at heart and often presented as health-conscious and physically active. Characters of this type can be described as beautiful, even glamorous, and it is shown through the narrative of the advertising that they take pride in their appearance. As such, they are individuals who appear welldressed, sophisticated and youthful, for example. At first glance, the Golden Agers might not appear to be of an older age, among others, due to their behavior; though on closer examination, the wrinkles on their faces or their graying hair becomes apparent. Nonetheless, they are always happy, smiling and clearly enjoying their advanced years. Whilst characters of this type are shown as independent, they may be in the company of an array of individuals from several different age groups. Golden Agers occur as both female and male characters, with a female skew in the sample, and are always under the age of 75 years. They frequently promote food and beverages, financial services and cosmetic products.

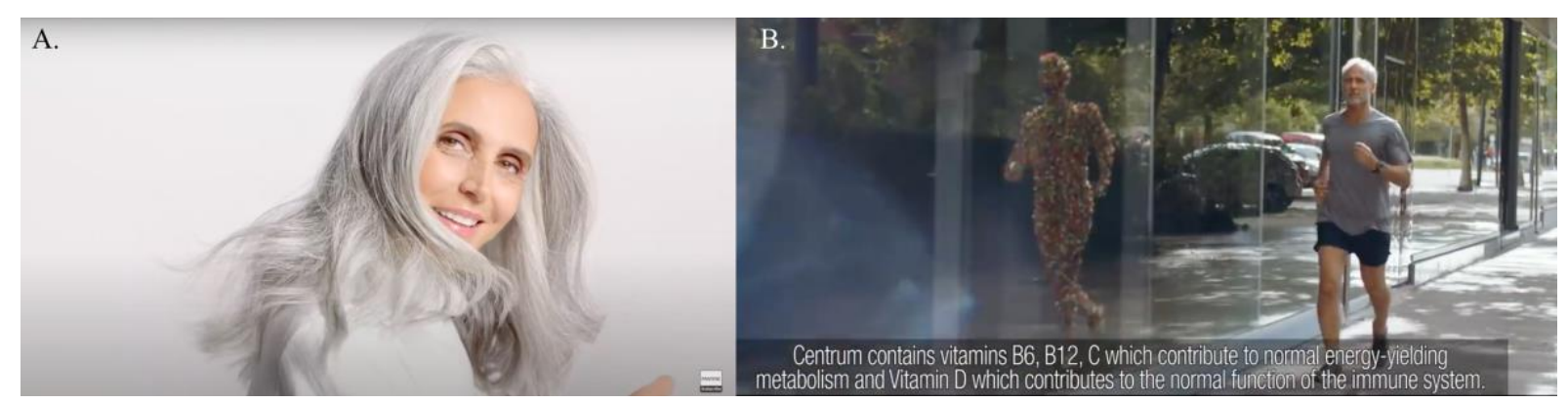

Figure 1: Examples of the Golden Ager

A. In this advert for Pantene, a well-dressed older woman moves dynamically during a photoshoot, confidently smiling into the camera. Standing with younger models as equals, she celebrates the beauty of her natural hair color. B. An older man is jogging outside, staying healthy and fit, whilst the off-camera commentary tells the audience about the energizing properties of Centrum vitamins.

\section{Perfect Grandparent}

The Perfect Grandparent is never alone — but surrounded by family, often made up of several generations. Narratives involving this type are always positive, showing happy and smiling individuals who are in good health, laughing and enjoying the company of others. Frequently, a Perfect Grandparent will be showing affection towards members of their family. Their advanced age is revealed not only by their role within the social setting, but also by their visual appearance, with age markers such as gray or white hair being apparent. However, stereotypical signs of frailty or old age illnesses are not present. The Perfect Grandparent appears in a variety of settings, for example, engaging in physical activities with their grandchildren, such as riding a bike, or simply sitting around a dinner table with their entire family. This type is evenly distributed between females and males, and ranges in age from adults in their 50s to those in their 70s. The Perfect Grandparent advertises a variety of product and services, but primarily food, beverages, and tourism.

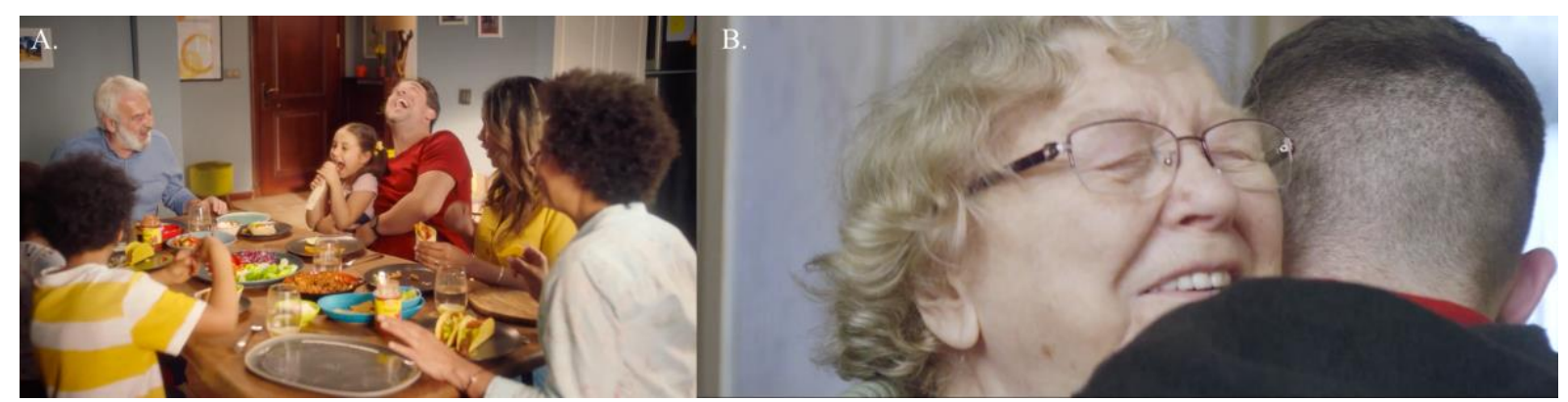

Figure 2: Examples of the Perfect Grandparent

A. A multigenerational family sits around the dinner table. While enjoying the meal, which was prepared with the help of Old El Paso, the oldest member of the family is seen happily interacting and joking with his granddaughter. B. An older woman is waiting in her kitchen doorway for her grandson to return from the Royal Navy. Once he arrived, she embraces him lovingly, appearing visibly happy and relieved.

\section{Mentor or Legacy}

This type is comprised of individuals who are experts or advisors, typically showcasing their great knowledge, wisdom and experience in relation to a particular field, product or service. Mentors or legacy characters are 
commonly found in business setting, such as seated behind a desk, with markers of power or wealth, such as wearing a business suit, that convey that the character is in a position of influence or is recognized as being successful. In addition, other characters will be looking to them for advice or approval. Whilst characters of this type show visible signs of aging, such as wrinkles, gray or receding hair, they will not typically be frail or have visible old-age impairments. Mentors or legacy characters are almost exclusively older men under the age of 65 years. Only very occasionally are they older; but never older than 75 years. Most commonly, this character type advertises for products from the food and beverage industry and a variety of services.

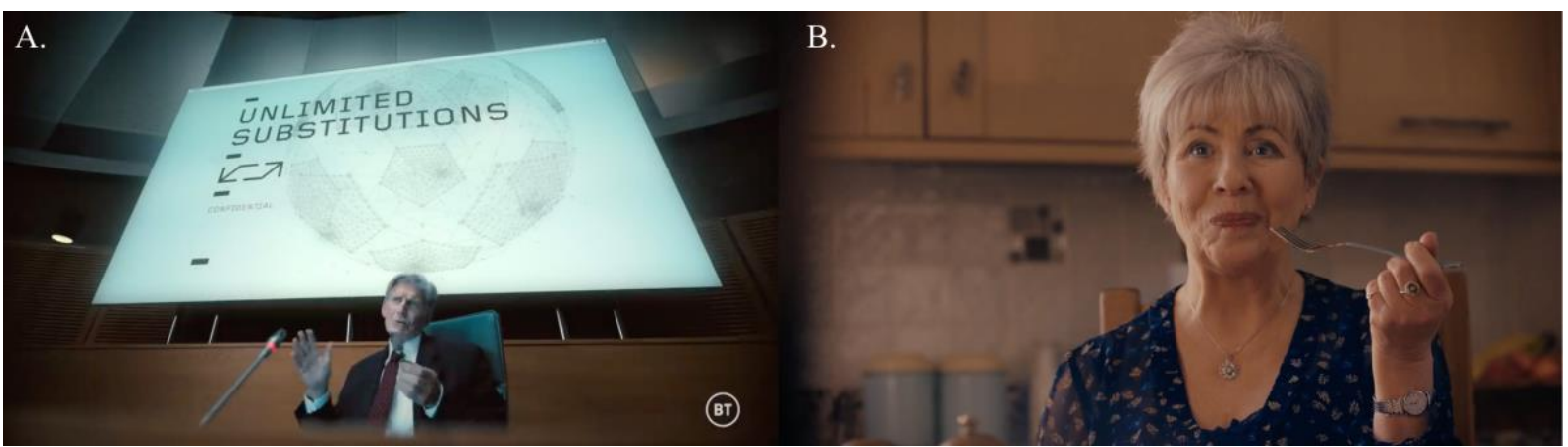

Figure 3: Examples of Mentor or Legacy

A. In this advert for $B T T V$, an older man in business attire is chairing a committee meeting. His demeanor and the low-shot camera angle imply authority, with other people taking notes of what he says. B. In this rare example of a female Mentor or Legacy type, an older woman sits with her family together for a meal; she initially looks stern. After her granddaughter has cooked the meal with the help of Princes tuna, the whole family is looking at her for approval. After taking a bite, she starts smiling and nods, resulting in relief amongst family members.

\section{Comedic}

Older characters of the Comedic type are to be found in humorous situations, and although we occasionally laugh with them, generally, the narratives are crafted in a way that makes us laugh at them. These humorous situations depicted are often ridiculous or absurd and unnatural or far-fetched, such as an older couple running down a hill to escape giant lottery balls hurtling toward them. We know of their advanced age due to physical identifiers; however, we do not laugh at them because of their age, but only due to the situations they find themselves in. It is usual to see Comedic types in outdoor settings, occasionally surrounded by others. Only very rarely are they the sole focus of a narrative. This type occurs as both female and male characters, with a female skew in the sample, and promotes mainly gambling services, as well as food and beverages.

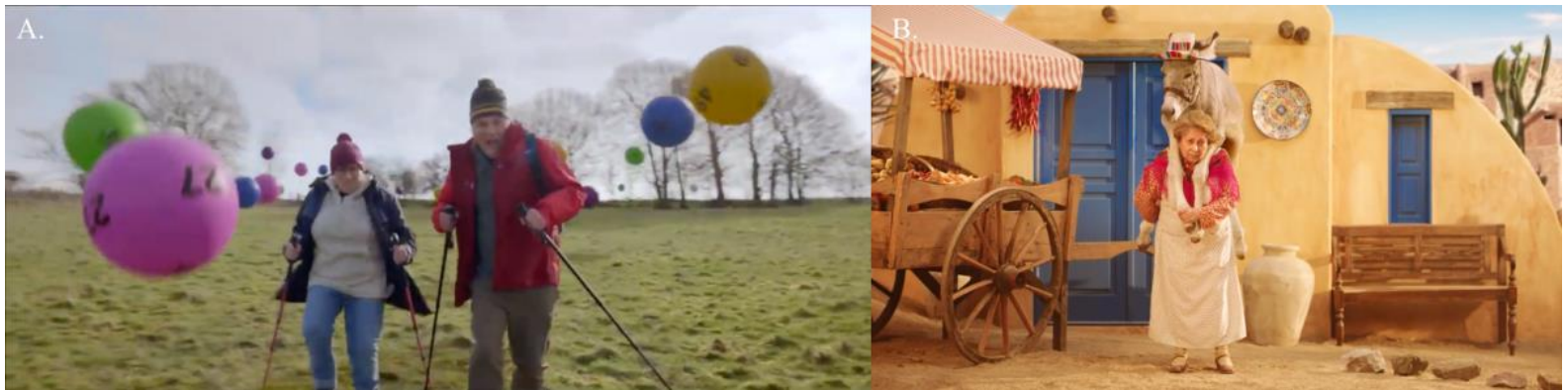

Figure 4: Examples of the Comedic type

A. In a commercial for the National Lottery, an older couple is hiking through the countryside. Trying to escape the suddenly-appearing giant lottery balls, the couple is chased downhill, before the scene cuts to other protagonists. B. A woman is standing outdoors in desert-like surroundings, holding an old-fashioned vegetable cart and carrying a donkey on her back. She looks straight at the audience; no explanation of the situation is provided. After taking a spoonful of Super Noodles, she smiles and licks her lips, before the commercial cuts away.

\section{Coper}

Characters of this type are older adults who live with a disability, and show stark physical, cognitive and/or social decline. These individuals are able to cope with their impairment or their situation because of the support or the aid from the product or service being advertised. This could be, for example, an older person cherishing the sound of birdsong thanks to a new hearing aid. Despite their situation, they are not despondent; instead, they are frequently shown to be happy and smiling. We can determine the Coper's age due to clear visual cues of wrinkles and gray, or even white, hair. This type is the most diverse in terms of ethnicity and age within the 
sample, and characters are more often than not female. Copers advertise a broad range of services, and products from the food and beverage industry.

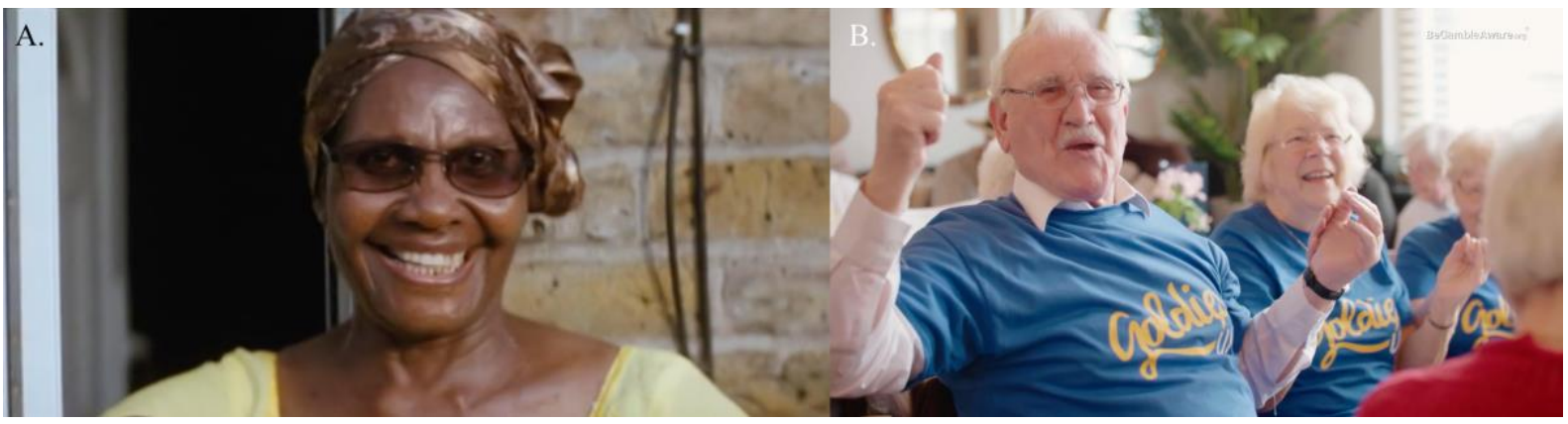

Figure 5: Examples of the Coper

A. This commercial by online grocer Ocado utilizes several older adults. The voice-over indicates that the persons shown are vulnerable members of society who were shielding during the UK's COVID-19 lockdown. Among others, it features an older woman stepping out of her front door as her groceries are delivered, visibly happy to see the delivery driver. B. A jolly group of older adults is shown in this advert for the People's Postcode Lottery. The caption reveals to the audience that these people are participating in singing therapy, which is frequently used to combat cognitive and social decline in old age.

\section{Celebrity Endorser}

In the narratives of the Celebrity Endorser, age takes a backseat to their social status. Characters of this type are well-known older adults in the public eye, who endorse a product or a service. We know who they are, so there is no need for dedicated identifiers, such as visual cues in the form of pronounced wrinkles or social settings, to appreciate their advanced age. Celebrity Endorsers often address the audience personally, looking directly at the camera and thus the viewer. Although they are celebrities, we do not see their lavish lifestyles; we may just see them sitting on a park bench, for example. They are shown to be conventional, so they are like us, in order that we might relate to them. Yet, due to their well-known social status, we trust their opinion as a seal of approval. Celebrity Endorsers are shown to be healthy and content with their age and are almost exclusively males. Most frequently, this type advertises for food and beverages, and for gambling services. It should be noted that advertising utilizing Celebrity Endorsers often go together with narratives that, if it was not for their social status, would qualify them for Mentors or Comedic types.

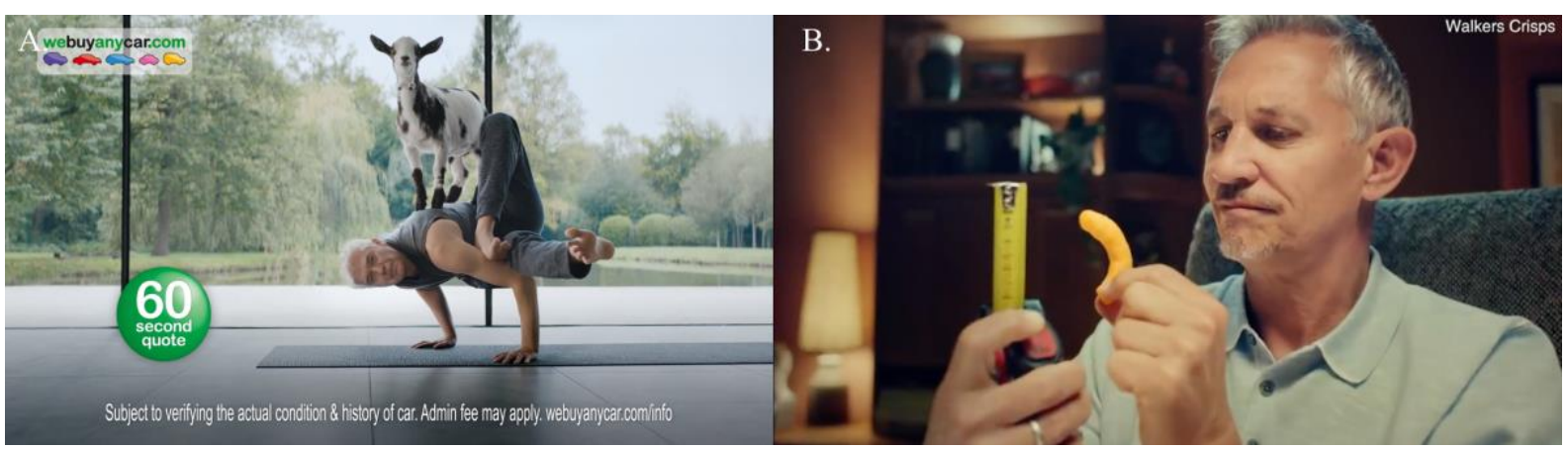

Figure 6: Examples of the Celebrity Endorser

A. British TV host Phillip Schofield is performing advanced yoga exercises, whilst balancing a goat on his back and talking to the audience about the benefits of using webuyanycar.com. B. Former English footballer, Gary Lineker, is sitting in his living room, measuring a Walkers corn puff, visibly impressed by its size.

In addition to the already existing types identified by Williams and colleagues, two new, distinct character types emerged during the analysis of the current sample: the 'Happy Couple' and the 'Jane or Joe Public'.

\section{Happy Couple}

Characters of this type can be seen with the person they love, being physically affectionate or gazing into each other's eyes. They are smiling and content, and we can assume they have enjoyed a long and loving relationship for many years. The Happy Couple and their bond are usually the primary focus at that specific moment in the narrative - the situations are often intimate, as we can see them, for example, dancing together, giving and receiving flowers or having a picnic in a park. Even on the occasion that there are other people around them, our focus is still entirely on the Happy Couple. There are clear, visible age markers, such as wrinkles and gray or 
white hair, demonstrating their advanced age. The Happy Couple is exclusively heterosexual, aged in their 50s and 60s, and primarily promotes tourism and household items.

What differentiates this type from Golden Agers is the narrative's focus on their affectionate relationship and interaction between each other, which overrides everything else. They also display more prominent visual age markers. The Happy Couple is not the Perfect Grandparent, due to a lack of immediate family interactionthat is, their attention is on each other rather than on their (grand)children. Also, unlike the Perfect Grandparent, the Happy Couple always appears together.

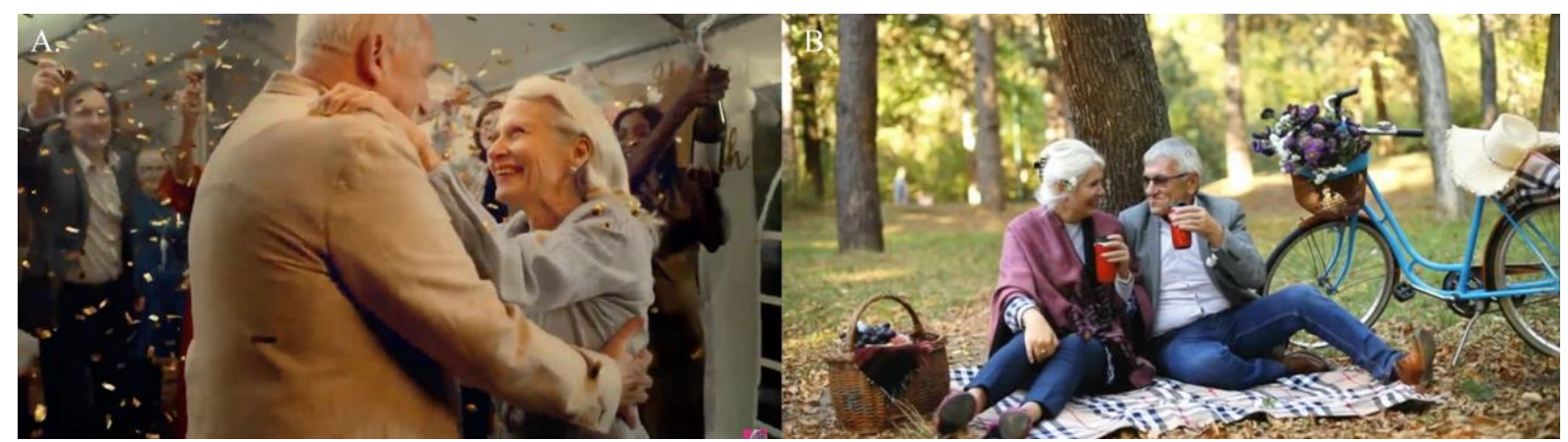

Figure 7: Examples of the Happy Couple

A. In this commercial for Vanish Gold Crystal White, an older couple is affectionately dancing with each other. Surrounded by other people who seemingly celebrate them, the focus is on the happy faces of the older adults. B. Sitting on a blanket in a park, an older couple is enjoying each other's company during a picnic in an advert for Parkdean Resorts.

\section{Jane or Joe Public}

The Jane or Joe Public is an older individual who is depicted as a typical member of society. They are often part of narratives that use a large range of characters in respect of age, sex and ethnicity, creating a reflection of members of a diverse society. As these characters are usually part of a wider community, they are never the sole focus of the narrative, but instead a friendly face amongst many. Characters show physical signs of aging, such as gray hair or wrinkles. It is worth noting that this type includes some of the oldest members of society and yet, age is never the focal point of the narrative. The Jane or Joe Public are like us, so we can relate to them. They partake in conventional, everyday activities, for example playing the lottery, going to the store or driving a car. If they are seen interacting with other individuals, it is always with people outside of their close family unit, such as neighbors. This type occurs as both female and male, with a distinct female skew in the sample, and mostly advertises entertainment and media, gambling and other services.

The Jane or Joe Public is distinct from other types as they are not part of a comedic narrative, or show health impairments. Their family ties and romantic relationship with others are also not further explored. They are simply a depiction of a slice of life as part of the narrative.

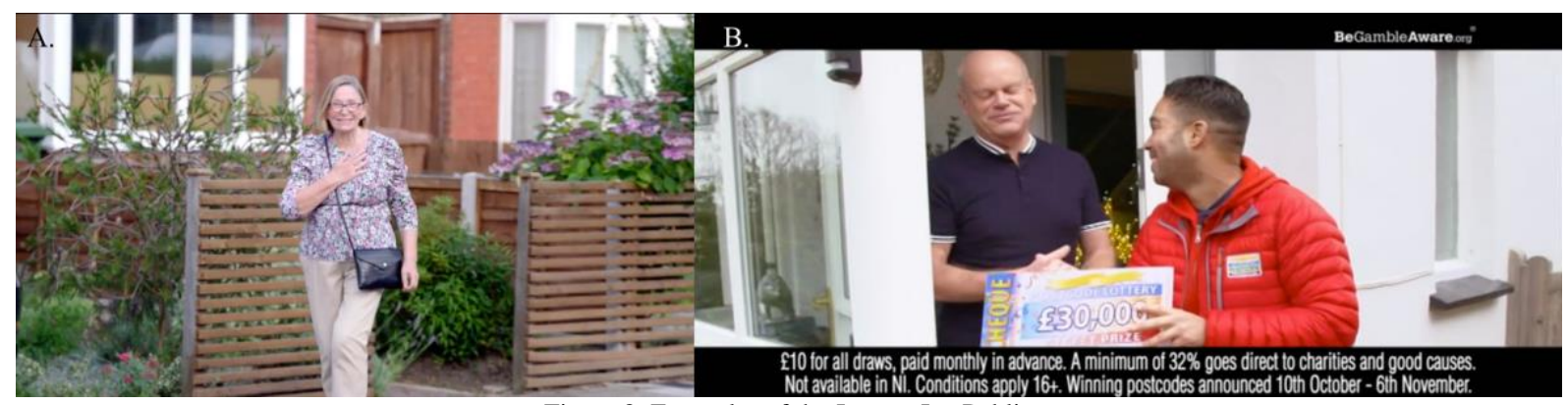

Figure 8: Examples of the Jane or Joe Public

A. A young family is getting on their bikes outside their home to go to the supermarket of their choice, Asda. An older woman-seemingly a neighbor-waves at them from across the street. They have a brief conversation before the scene cuts away. B. An older man steps through the front door of his house and is in disbelief when being informed about his lottery win. He is one of many winners sharing the spotlight in this commercial by the People's Postcode Lottery.

\section{Discussion and Conclusion}

The current investigation indicates that all character types identified by Williams and colleagues (2010) still prevail in 2020. However, with almost one in four older protagonists not fitting any of the pre-determined types, 
these evidently do not cover the full range of stories told with older characters in current British TV advertising. It appears that the ageist constrictions, observed in the studies from over a decade ago, have loosened and the range of types and functions admitted to older adults in advertising has broadened. This is in line with Ylänne's (2020) findings for magazine advertising, where one in ten older protagonists did not fit any of the predetermined types. The two new proposed character types of the present study - the 'Happy Couple' and the 'Jane or Joe Public' — can be considered as positively and neutrally connoted additions to the existing six types. Particularly noteworthy with the newly identified character types are the frequent portrayal of romantic relationships and physical contact between older adults; thus, taking a step towards narratives that break with long-standing, ageist taboos, such as sexuality in older age (Royal College of Nursing 2019). The slice of life nature of the 'Jane or Joe Public' further normalizes the use of older adults in a variety of settings. It appears a positive development that as part of a rolodex of multi-generational characters in these adverts, older adults generally do not receive more or less screen time than younger protagonists.

Whilst at first glance the changes in the distribution of types compared to previous studies indicate a shift in the utilization of individual character types, it should be noted that these changes might be, at least in part, due to the different sample compositions of the studies. Both Williams et al. (2010) and Ylänne (2020) focused their research on print magazines specifically targeted at older readers. This might explain the higher frequency of positively (e.g., Golden Ager) and negatively (e.g., Coper) connoted types in their studies, as advertising placed in these magazines is more likely to sell a variety of aspirational products and services to its audiences, and, at the same time, address age-related impairments more openly in order to sell their suggestions for easing the ailments. However, what can be taken from the comparison is that there appears to be a different emphasis in terms of the ideas of aging and old age that are conveyed to older audiences compared to the broader public. Accordingly, we see less pronounced extremes of affluence and eternal youthfulness and sickly or impaired older adults in the portrayals offered to the broader public. In contrast, it appears to be much more acceptable to put an older character at the center of a joke, when the persuasive message is not exclusively targeted at older persons.

To what extent these findings refute the claim of ongoing ageism by the Centre for Ageing Better (2020) requires further investigation into other forms of media. Nonetheless, a more varied portrayal of older people in contemporary print and TV advertising has likely led to less repetition of the same types of behaviors in the portrayal of older characters, and thus to the reduction of one of the features of ageism. Whilst "a full range of human potentials" (Ansello 1977, 255), as the proposed antithesis to ageism, is still not the case, this aim might be unrealistic to achieve with advertising, or media content more generally. The nature of mass media, with its time constraints in terms of production and limited attention on the part of the audience, will to some degree always need to resort to abstract character types and functions for its storytelling. However, while it might be difficult to completely avoid a limitation of human potential in media portrayals, this should not stop researchers from monitoring if and how these are changing and, hopefully, further break free from existing limitations; thus, indicating shifts in the minds of the people who create and consume the media content. This paper has contributed to the discourse on this topic by investigating the current portrayal of older adults in British advertising and by examining the applicability of Williams et al.'s (2010) proposed typology. In addition, our research updated the existing typology, by identifying and contextualizing two new character types. Lastly, the study provided detailed descriptions for each type, which ought to facilitate more meaningful comparisons for future research into the topic.

\section{EXAMPLE TV AVERTISING}

A curated playlist, featuring all example commercials referenced in this paper, can be found on Box of Broadcast (BoB): https://learningonscreen.ac.uk/ondemand/playlists/315654

Where obtainable through a brand's public communication channels, links to the commercials are also provided below. Alas, only a select few referenced examples could be accessed via public channels.

Golden Ager (A): "Pantene Pro-V Hair Biology", https://www.youtube.com/watch?v=7w2HbFWSvwM

Golden Ager (B): “Centrum GB Immunity TV Ad 2020”, https://www.youtube.com/watch?v=6y-ci2F8ufo

Perfect Grandparent (A): "Make some noise - Old El Paso", https://www.youtube.com/watch?v=8V9HkofqaaE

Mentor or Legacy (B): "Princes SPRINGWATER 2019”, https://www.youtube.com/watch?v=jHIhWRIZf_k

Celebrity Endorser (A): "Goat Yoga | 60 Second Valuation", https://www.youtube.com/watch?v=MKxwKhaGmRI

Happy Couple (A): "Vanish Gold Crystal White Gels - Love Your Whites For Longer", https://www.youtube.com/watch?v=e7kRFmTZI-I

Jane or Joe Public (A): “That's Asda Price TV Advert | Asda”, https://www.youtube.com/watch?v=4oFQ0Eg10wo

Jane or Joe Public (B): "Thirty Thousand Pounds - July Draws - People's Postcode Lottery", https://www.youtube.com/watch?v=wdVWu5 $-\mathrm{aO} 5 \mathrm{o}$ 


\section{REFERENCES}

Ansello, Edward F. 1977. “Age and ageism in children's first literature.” Educational Gerontology 2 (3): 255 274. http://doi.org/10.1080/0360127770020305

Berger, Charles R. 2005. "Slippery slopes to apprehension: Rationality and graphical depictions of increasingly threatening trends." Communication Research 32 (1): 3-28. http://doi.org/10.1177\%2F009365020427 1397

Busselle, Rick, and Jan Van den Bulck. 2020. "Cultivation Theory, Media Stories, Processes, and Reality." In Media Effects. Advances in Theory and Research, edited by Mary Beth Oliver, Arthur A. Raney, and Jennings Bryant, 69-82. New York: Routledge. http://doi.org/10.4324/9780429491146-5

Butler, Robert. 1975. Why survive? Being old in America. New York: Harper \& Row.

Bryant, Jennings. 1986. "The road most traveled. Yet another cultivation critique." Journal of Broadcasting \& Electronic Media 30: 231-235. https://doi.org/10.1080/08838158609386621

Centre for Ageing Better. 2020. Exploring representations of old age and ageing. London: Centre for Ageing Better. https://www.ageing-better.org.uk/publications/doddery-dear-examining-age-related-stereotypes

Cluley, Robert. 2017. Essentials of Advertising. London: Kogan Page.

Ehala, Martin. 2010. "Ethnolinguistic vitality and intergroup processes.” Multilingua 29 (2): 203-221. https://doi. org/10.1515/mult.2010.009

Eurostat. 2021. "Population structure and ageing.” Accessed February 16, 2021. https://ec.europa.eu/eurostat/data browser/view/tps00010/settings_1/table?lang=en.

Gerbner, George, Larry Gross, Michael Morgan, Nancy Signorielli, and James Shanahan. 2002. "Growing up with television: Cultivation Processes.” In Media Effects. Advances in Theory and Research, edited by Jennings Bryant, and Dolf Zillmann, 43-68. Mahwah: Lawrence Erlsbaum Associates.

Griffin, Em. 2012. Communication Communication Communication: A first look at communication theory. New York: McGraw-Hill.

Hall, Stuart, Chas Critcher, Tony Jefferson, John Clarke, and Brian Roberts. 1978. Policing the Crisis. Mugging, the State, and Law and Order. London: Macmillan Education.

Harwood, Jake, and Abhik Roy. 2005. "Social identity theory and mass communication research." In Intergroup communication: Multiple perspectives, edited by Jake Harwood, and Howard Giles, 189-212. New York: Peter Lang.

Hasebrink, Uwe. 2016. "Kultivierung." [Cultivation] In Medien von A bis $Z$ [The media form a to z], edited by Hans-Bredow-Institut, 188-191. Wiesbaden: Springer VS. https://doi.org/10.1007/978-3-531-90261-6_ 82

Hesse, Kurt R., and Astrid Gelzleichter. 1993. "Images und Fernsehen.” [Images and Television] In Theorien öffentlicher Kommunikation - Problemfelder, Positionen, Perspektiven [Theories of public communcations - problem areas, opinions, perspectives], edited by Günter Bentele, and Manfred Rühl, 409-434. Munich: UVK.

Idris, Izian, and Lynn Sudbury-Riley. 2016. "The Representation of Older Adults in Malaysian Advertising." The International Journal of Aging and Society 6 (3): 1-16. https://doi.org/10.18848/21601909/CGP/v06i03/ 1-16

Kessler, Eva-Marie, Clemens Schwender, and Catherine E. Bowen. 2010. “The portrayal of older people's social participation on German prime-time TV advertisements." Journal of Gerontology: Social Sciences 65B (1): 97-106. https://doi.org/10.1093/geronb/gbp084 
Koinig, Isabell, Sandra Diehl, and Ralf Terlutter. 2020. "Gender-Role Portrayals in Advertising: State of the Art and Cross-Cultural Differences." The International Encyclopedia of Gender, Media, and Communication, 1-7. https://doi.org/10.1002/9781119429128.iegmc198

Lester, Paul Martin. 1997. "Images and Stereotypes.” In Contemporary Ethical Issues: Journalism, edited by Elliot D. Cohen, and Deni Elliott. Santa Barbara: ABC-CLIO.

Lombard, Matthew, Jennifer Snyder-Duch, and Cheryl C. Bracken. 2002. "Content analysis in mass communication research: An assessment and reporting of intercoder reliability." Human Communication Research 28 (4): 587-604. https://doi.org/10.1111/j.1468-2958.2002.tb00826.x

Macnamara, Jim. 2005. "Media content analysis: Its uses, benefits and best practice methodology." Asia Pacific Public Relations Journal 6 (1): 1-34. https://doi.org/10453/10102

O'Barr, William M. 2012. "Sexuality, Race, and Ethnicity in Advertising.” Advertising \& Society Review 13(3).

Olsen, Dennis A. 2019a. "How it all began: A history of scholarship on the representation of older adults in German advertising." In Exploring Identity Building: Marketing History as an Instrument of Transformation, edited by Val Larsen, 139-156. Saskatoon, Canada: University of Saskatchewan Press.

Olsen, Dennis A. 2019b. "Loneliness as an Activation Strategy in Narratives of Contemporary Advertising." In Emotions and Loneliness in a Networked Society, edited by Bianca Fox, 239-251. London: Palgrave Macmillan.

Otrebski, Dennis A. 2015. "Greying Societies: The value of looking at the growing group of the elderly through the looking glass of Media Studies." New Vistas 1 (2): 4-9.

Rossow, Judith, and Amei Koll-Stobbe. 2015. "Diskursive Konstruktionen und Reflektionen von Altersbildern Ein Blick auf Sprache und Interaktionsnormen.” [Discursive constructions and reflections of images of old age - A look at language and interaction norms] Journal für Psychologie [Journal of psychology] 23 (1): 31-54.

Royal College of Nursing. 2019. “Aspects of Age.” Accessed February 16, 2021. https://www.rcn.org.uk/libraryexhibitions/aspects-of-age.

Schmidt, Siegfried J., and Brigitte Spieß. 1995. Werbung, Medien und Kultur [Advertising, Media and Culture]. Opladen, Wiesbaden: Westdeutscher Verlag.

Schwender, Clemens, Dagmar Hoffmann, and Wolfgang Reißmann. 2013. Screening Age: Medienbilder, Stereotype, Altersdiskriminierung. [Screening age: media images, stereotypes, age discrimination]. Munich: Kopaed.

Schwender, Clemens. 2015. "Geschlechtsspezifische Altersrollen in der Werbung." [Gender-specific age roles in advertising] In Gender - Medien - Screens. (De)Konstruktionen aus wissenschaftlicher und künstlicher Perspektive [Gender - Media - Screens. Scholarly and artistic (de)constructions], edited by Elizabeth Prommer, Martina Schuegraf, and Claudia Wegener, 65-83. Munich: UVK.

Whitfield, Corinna. 2001. "Benign or malign? Media stereotyping.” Nursing Older People 13 (6): 10-13. https:// doi.org/10.7748/nop.13.6.10.s12

Williams, Angie, Virpi Ylänne, Paul Mark Wadleigh, and Chin-Hui Chen. 2010. "Portrayals of older adults in UK magazine advertisements: Relevance of target audience.” Communications 35 (1): 1-27. https://doi.org/10 .1515/comm.2010.001

Ylänne, Virpi. 2020. "Media Positionings of Older People.” In Changing Horizons in the 21st Century: Perspectives on Ageing, edited by Amanda Phelan, and Diarmuid O’Shea, 306-318. Newcastle Upon Tyne: Cambridge Scholars Publishing. 


\section{ABOUT THE AUTHORS}

Dr Dennis A. Olsen: Senior Lecturer in Advertising and Branding in the London School of Film, Media and Design at the University of West London, London, United Kingdom.

Charlotte Scott: Research Assistant in the London School of Film, Media and Design at the University of West London, London, United Kingdom.

Olsen, Dennis, and Charlotte Scott. 2021. "Golden Years, Wise Mentors and Old Fools: An Updated Typology of Older Characters in British TV Advertising." The Journal of Aging and Social Change, TBC. (C) Common Ground Research Networks, Authors, All Rights Reserved. Permissions: cgscholar.com/cg_support. 